$\xi=-1$

\title{
Correlation of Spiritual Well-being Psychological Capital among University Students-Iran
}

\author{
Reza Pourmirza Kalhori ${ }^{1}$, Hakimeh Mohammadzadeh ${ }^{2 *}$, Azadeh Foroughinia ${ }^{1}$, Neda Kianipour ${ }^{3}$ \\ ${ }^{1}$ Emergency Medical Department, Paramedical School, Kermanshah University of Medical Sciences, Kermanshah, Iran \\ ${ }^{2}$ Shoushtar Facultiy of Medical Sciences, Shoushtar, Iran \\ ${ }^{3}$ Students Research Committee, Kermanshah University of Medical Sciences, Kermanshah, Iran \\ *Corresponding author_E-mail: hk.mo_2012@yahoo.com
}

\begin{abstract}
Psychological capital is one of the new concepts raised in positivism in psychology, which can play a major role in increasing one's ability in different aspects of life, especially in spiritual well-being. Therefore, the present study aimed to investigate the relationship between the components of spiritual well-being and psychological capital of students at Kermanshah University of Medical Sciences, Iran in 2017. In this descriptive-correlational study, the statistical population consisted of 400 students at Kermanshah University of Medical Sciences, who were selected through cluster sampling. To collect the required data, a demographic questionnaire, the spiritual well-being scale (SWB) by Paloutzian \& Ellison and the Psychological Capital Questionnaire (PCQ) by Luthans were used. In addition, the data were analyzed using the SPSS Statistics Software Version 23.0. The results of the present study revealed that the mean scores of students' spiritual well-being and psychological capital measured $3.60 \pm 0.49$ and $3.55 \pm 0.44$, respectively. Further, the results of Pearson correlation coefficient indicated that the students' spiritual well-being and psychological capital positively and significantly correlated $(\mathrm{r}=0.42)$. According to the findings of the present study, the students' spiritual well-being affects their psychological capital. So, it can be concluded that religious orientation and spirituality can promote the psychological capital of individuals, and this approach can be used to provide services relating to mental well-being.
\end{abstract}

Keywords: Spiritual well-being, Psychological Capital, University Students.

\section{Introduction}

Psychological capital is one of the indexes of positivism in psychology, which is defined with characteristics such as belief in one's ability to succeed, perseverance in pursuing goals, creating positive attributes, and bearing problems [1]. Psychological capital, derived from positive organizational behavior, is a new concept that has recently been introduced by Luthans. This concept consists of factors such as hope, optimism, and selfefficacy [2,3]. Self-efficacy means one's belief and confidence in one's ability to succeed in performing tasks [4-6]. Resilience is a toughness indicator, which means how constructively one works under hard circumstances. Those with high resilience are able to keep on trying and coping with situations effectively in the face of unpleasant and stressful situations and events towards success [79]. In addition, optimistic people associate positive events in life with permanent and personal factors, and vice versa $[10,11]$. Hope is also a state whereby one is able to identify real, challenging, attractive, accessible, and predictable goals for himself/herself, thereby encouraging them to achieve their desired goals $[12,13]$.

On the other hand, alongside the psychological capital, spiritual well-being conceptually goes back to the fact that one is able to interact inwardly with himself/herself and the creator of the universe who is the source of the truth and continues to function purposefully with the meanings and values in which he/she believes [14-16]. In fact, spiritual well-being is the newest dimension of well-being, along with other well-being issues such as physical, psychological, and social well-being [17-19]. Spiritual well-being has two aspects: religious and existential. Religious well-being reflects one's relationship with God or an absolute power, whereas existential well-being also includes one's relationship with onseself, others, and the environment. In general, it can be understood as the ability to integrate different aspects of existence and to have different choices $[15,20]$. In fact, it seems that one's enjoyment of spiritual well-being, especially the youth, will equip him/her with beliefs and attitudes, thereby leading to positive outcomes for the person, such as psychological capital [21-23].

In a study performed by Golparvar [24], the results indicated that psychological capital laid the groundwork for spiritual well-being and the establishment of coherence and consistency in meaning, purpose and supreme values of the world in the life of nurses. Culbertson et al. [25] expressed that more satisfaction, vitality and well-being were reported by university students with higher psychological capitals. The results of a study conducted by Bayrami and Movahedi [26] showed that social skills training affected all components of psychological capital. In addition, Golparvar [24] reported that psychological capital significantly and positively correlated with spiritual well-being. Similarly, it was shown that there was a positive and significant relationship between psychological capital and each of spiritual well-being and mindfulness. Taheri Kharameh et al. [27] revealed that there was a significant correlation between spiritual-religious well-being and mental well-being. 
Additionally, as for the role of spiritual well-being in optimism and hope, research has that in the face of hardships, such as chronic illnesses or in the aging period, one is able to keep on with life happily provided that he/she is equipped with spiritual wellbeing $[28,29]$.

Since students are considered the main pillars of human resources in any country, and given the importance of the role of students in the development of societies, it is natural that the study of the factors affecting the growth, satisfaction of psychological needs and physical and psychological well-being of this stratum is of particular importance [30,31]. On the one hand, entrance to university is seen as a major event in the lives of efficient and active young people in any country, which is often accompanied by a lot of changes in their social and individual relationships [32, 33]. Therefore, due to the significance of the issue of spiritual well-being and psychological capital in students and considering that there was no study on the students of Kermanshah University of Medical Sciences, the present study aimed to investigate the relationship between the components of spiritual well-being and psychological capital of students at Kermanshah University of Medical Sciences, Iran in 2017

\section{Method}

In this descriptive-correlational study, the statistical population consisted of 400 students studying at Kermanshah University of Medical Sciences in 2017, who were selected through cluster sampling. To collect the required data, a demographic questionnaire, the spiritual well-being scale (SWB) by Paloutzian \& Ellison and the Psychological Capital Questionnaire (PCQ) by Luthans were used. In addition, the inclusion criteria were agreement to participate in the research and studying in the second semester of the academic year 2017 whereas the incomplete questionnaires were excluded from the study.

Demographic Questionnaire: The first part of the instrument dealt with the demographics and comprised questions on gender, age, marital status, mode of residence, faculty, and education.

Spiritual Well-being Scale (SWB): The second part was the 20item spiritual well-being scale developed by Paloutzian \& Ellison [34]. The scale comprised two parts: religious and existential, with 10 questions in each part on six-point Likert scale, attracting a score in the range of 10 to 60 . More to the point, for the positively worded questions, the numerical scoring scale run as follows: $1=$ strongly disagree, $2=$ disagree, $3=$ somewhat disagree, $4=$ somewhat agree, $5=$ agree, $6=$ strongly agree. Conversely, for negatively worded questions, the reverse scoring was employed as follows: $1=$ strongly agree, $2=$ agree, $3=$ somewhat agree, $4=$ somewhat disagree, $5=$ disagree, $6=$ strongly disagree. The total score of the total spiritual well-being ranges from 20 to 120 . In sum, the status of spiritual well-being was categorized as follows: low (20-40), average (41-99), and high (100-120) [35]. This questionnaire has been used in various studies both inside and outside Iran, and its reliability and validity have been confirmed $[36,37]$.
Psychological Capital Questionnaire (PCQ): The third part was the psychological capital scale developed by Luthans [2] with 24 questions in each part on a six-point Likert scale ( $1=$ strongly disagree, $\ldots 6=$ strongly agree). The questionnaire comprised four subscales: self-efficacy, hope, resilience, and optimism. Selfefficacy means one's belief in one's ability to succeed in performing tasks (Questions 1-6), whereas hope is also a state whereby one is able to identify real, challenging, attractive, accessible, and predictable goals for himself/herself, thereby encouraging them to achieve their desired goals (Questions 7-12). Additionally, resilience is indicative of one's hardiness in hard conditions and functioning constructively.

Those with high resilience are able to keep on trying and coping with situations effectively in the face of unpleasant and stressful situations and events towards success (Questions 13-18). In addition, optimistic people associate positive events in life with permanent and personal factors, and vice versa (Questions 19-24). Moreover, a high score in this questionnaire denotes more psychological capital. As for the reliability of this scale, a Cronbach's alpha coefficient of 0.79 was reported in a study performed by Shakrami et al. [7].

\section{Findings}

Of the total of 400 subjects in the present study, 200 students $(50 \%)$ were male and $200(50 \%)$ were female. The average age of the subjects was $22.90 \pm 3.17$, and the majority of subjects were aged between 19 and 22 (57\%). In terms of marital status, 371 of the participants $(92.8 \%)$ were single. In addition, the majority of students were studying bachelor (253 students or $63.2 \%$ ). The number of students at each faculty was similar (25\%). Further, the majority of students were living in dormitories (233 students or $58.3 \%$ ) (Table 1)

Findings showed that the mean and standard deviation of the total spiritual well-being of university students were $3.60 \pm 0.49$. As for the dimensions of students' spiritual well-being, the results revealed that the dimensions of religious and existential wellbeing had the highest and lowest means $(3.75 \pm 0.77$ and $3.45 \pm 0.47$, respectively) (Table 2)

Findings also showed that the mean and standard deviation of the psychological capital of university students measured 3.55 \pm 0.44 . As for the dimensions of students' psychological capital, the results indicated that hope and resilience had the highest and lowest means (3.81 \pm 0.57 and $3.37 \pm 0.63$, respectively) (Table 2 ). In addition, the results indicated that all of the components of psychological capital significantly and positively correlated with students' spiritual well-being $(\mathrm{p}<0.01)$. In this regard, the results of Pearson correlation coefficient revealed that spiritual well-being had a significant correlation with each of self-efficacy, resilience, optimism, hope and the total score of psychological capital with correlation coefficients of $0.15,0.19,0.38,0.29$ and 0.42 , respectively (Table 3 )

Table 1:. The Participants' Demographic Characteristics (N=400)

\begin{tabular}{|l|c|c|}
\hline Variables & Groups & Number (\%) \\
\hline \multirow{2}{*}{ Gender } & Female & $200(50 \%)$ \\
\hline \multirow{3}{*}{ Age, y } & Male & $200(50 \%)$ \\
\cline { 2 - 3 } & $19-22$ & $228(57 \%)$ \\
\hline \multirow{3}{*}{ Marital Status } & $23-26$ & $105(26.3 \%)$ \\
\hline \multirow{4}{*}{ Education } & $27-30$ & $67(16.8)$ \\
\cline { 2 - 3 } & Single & $371(92.8 \%)$ \\
\cline { 2 - 3 } & Married & $29(7.2 \%)$ \\
\hline Faculty & Associate Degree & $42(10.5 \%)$ \\
\cline { 2 - 3 } & Bachelor's degree & $253(63.2 \%)$ \\
\cline { 2 - 3 } & Master's degree & $39(9.8 \%)$ \\
\cline { 2 - 3 } & PhD & $66(16.5)$ \\
\hline
\end{tabular}




\begin{tabular}{|c|c|c|}
\hline & Paramedics & $100(25 \%)$ \\
\hline & Nursing and Midwifery & $100(25 \%)$ \\
\hline & Well-being & $100(25 \%)$ \\
\hline \multirow{2}{*}{ Mode of Residence } & Dormitory & $233(58.3 \%)$ \\
\hline & Living with family & $89(22.3 \%)$ \\
\hline
\end{tabular}

Table 2:. The Mean and SD of the Research Variables

\begin{tabular}{|c|c|c|}
\hline \multicolumn{2}{|c|}{ Statistical Indexes } & \multirow{2}{*}{ Mean \pm SD } \\
\hline Scales & Subscales & \\
\hline \multirow[b]{2}{*}{ Spiritual well-being } & Religious Well-being & $3.75 \pm 0.77$ \\
\hline & Existential Well-being & $3.45 \pm 0.47$ \\
\hline \multirow{5}{*}{ Psychological Capital } & Hope & $3.81 \pm 0.57$ \\
\hline & Optimism & $3.60 \pm 0.62$ \\
\hline & Self-Efficacy & $3.39 \pm 0.69$ \\
\hline & Resilience & $3.37 \pm 0.63$ \\
\hline & Total Psychological Capital & $3.55 \pm 0.44$ \\
\hline
\end{tabular}

Table 3:. The Correlation Coefficients between the Research Variables

\begin{tabular}{|c|c|c|c|c|c|c|}
\hline Variable & Self-efficacy & Resilience & Optimism & Hope & Psychological Capital & Spiritual Well-being \\
\hline Self-efficacy & 1 & & & & \\
\hline Resilience & $0.46^{* *}$ & 1 & & & \\
\hline Optimism & $0.48^{* *}$ & $0.57^{* *}$ & 1 & & \\
\hline Hope & $0.33^{* *}$ & $0.26^{* *}$ & $0.43^{* *}$ & 1 & \\
\hline Psychological Capital & $0.75^{* *}$ & $0.56^{* *}$ & $0.33^{* *}$ & $0.59^{* *}$ & \\
\hline Spiritual well-being & $0.15^{* *}$ & $0.19^{* *}$ & $0.38^{* *}$ & $0.29^{* *}$ & 1 \\
\hline
\end{tabular}

$* * \mathrm{P}<0.01$

\section{Discussion}

The present study aimed to investigate the relationship between the components of spiritual well-being and psychological capital of students at Kermanshah University of Medical Sciences, Iran in 2017. The results of the present study demonstarted that there was a positive and significant relationship between the students' spiritual well-being and psychological capital. It can be said that the higher levels of spiritual well-being in students leads to a rise in their psychological capital. Also, spiritual well-being is a good predictor of psychological capital. These findings were consistent with the results of studies performed by Ghasemi-Jobaneh et al., [38] and Womble et al, [39]. The results of a study conducted by Golparvar [24] showed that psychological capital could significantly predict the spiritual well-being in nurses. Additionally, the results of a study by Culbertson et al. [25] revealed that students with higher levels of psychological capital would experience more satisfaction, vitality, and well-being. The results of a study conducted by Ghasemi-Jobaneh et al. [38] revealed that spiritual well-being and mindfulness had a positive and significant relationship with psychological capital. Moreover, Gnanaprakash study [40]reported that spiritual well-being directly correlated with reducing the perceived stress, increasing the effective coping styles, and consequently increasing the level of resilience in students. Fisher [41] expressed that there was a positive relationship between spirituality and each of well-being, happiness and inner satisfaction, which can be much affected by individuals' spiritual and mental atmosphere. Furthermore, Sessanna et al. [42] also pointed out that spirituality can be a key factor in increasing self-efficacy, hope, optimism, and consequently well-being. On the other hand, according to Bandura, individuals with high perceived self-efficacy trust their ability to overcome problems and achieve goals. Students who believe in their abilities can better address the challenges of the school environment $[43,44]$. At the same time, in the introduction of the components of psychological capital, especially in the field of self-efficacy and hope, such factors as purposefulness and the tendency to flourish one's abilities have been mentioned, and in the field of resilience and optimism (positive orientation to life), purposeful effort and perseverance have been mentioned [45-47].
These suggestions indicate that both spirituality and psychological capital have positive orientation.

To further explicate the relationship between the spiritual wellbeing and psychological capital, when one is optimistic, selfefficient and psychologically hopeful, he/she will be more capable of coherence and consistency in meaning, purpose, and value. In other words, psychological capital will place them in a more favorable position in terms of spiritual well-being through increasing the level of individuals' psychological empowerment, thereby leading to the link between psychological capital and spiritual well-being

\section{Limitation}

The main limitation of the present study was data collection using a self-report method, which may affect the accuracy of the results. In addition, the personal differences of the samples may also affect the generalizability of the research findings.

\section{Conclusion}

According to the findings of the present study, the students' spiritual well-being affects their psychological capital. So, it can be concluded that religious orientation and spirituality can promote the psychological capital of individuals, and this approach can be used to provide services relating to mental wellbeing.

Conflict of Interests: The authors declare no conflict of interest.

\section{References}

[1] Avey JB, Patera JL, West BJ. The implications of positive psychological capital on employee absenteeism. Journal of Leadership \& Organizational Studies. 2006;13(2):42-60.

[2] Luthans F, Luthans K, Luthans B. Positive Psychological Capital: Going bgehond human and social capital. Bus horiz 2004;47(1):45-50.

[3] Jelodar SM, Jelodar MB, Malmir M, Ziapour A. Factors affecting the excitement and violence in football (a survey on spectators and fans of 
Esteghlal and Persepolis). Social Sciences (Pakistan) 2016;11(10):2541-6.

[4] Masoudi Alavi N. Self-efficacy in nursing students. Nursing and midwifery studies. 2014;3(4):e25881.

[5] Ziapour A, Kianipour N. Health-related Quality of Life among University Students: The Role of Demographic Variables. Journal of Clinical and Diagnostic Research. 2018;12(3):JC01 - JC4.

[6] Abbasi P, Kianipour N, Ziapour A. A Study of the Status of Students Social Health at Kermanshah University of Medical Sciences and the Role of Demographic Variables. Journal of Clinical and Diagnostic Research. 2018;12(5):VC10-VC4.

[7] Shakarami M, Davarniya R, Zahrakar K. Predictor Factors of Psychological Well-being in Students. Quarterly Journal of Sabzevar University of Medical Sciences 2014;21(3):461- 81.

[8] Abbasi P, Timareh M, Ziapour A, Kianipour N. a study of the components of happiness and the role of demographic variables among the students at kermanshah university of medical sciences. Journal of Postgraduate Medical Institute. 2018;32(2):173-8.

[9] Zokaei A, Ziapour A, Kianipour N. Evaluation of Relationship between Organizational Culture and Job Satisfaction among Employee of Kermanshah University of Medical Sciences. The Social Sciences. 2016;11(16):4005-12

[10] Tugade MM, Fredrickson BL, Feldman Barrett L. Psychologica resilience and positive emotional granularity: Examining the benefits of positive emotions on coping and health. Journal of personality. 2004;72(6):1161-90.

[11] Pourmirza Kalhori R, Ziapour A, Kianipour N, Foroughinia A. A study of the relationship between lifestyle and happiness of students at Kermanshah University of Medical Sciences over 2015-2016. Annals of Tropical Medicine and Public Health. 2017;10(4):1004-9.

[12] Christens BD, Collura JJ, Tahir F. Critical hopefulness: A personcentered analysis of the intersection of cognitive and emotional empowerment. American Journal of Community Psychology. 2013;52(1-2):170-84

[13] Kaboudi M, Dehghan F, Ziapour A. The effect of acceptance and commitment therapy on the mental health of women patients with type II diabetes. Annals of Tropical Medicine and Public Health 2017:10(6):1709-13.

[14] Li C-C, Rew L, Hwang S-L. The relationship between spiritual wellbeing and psychosocial adjustment in Taiwanese patients with colorectal cancer and a colostomy. Journal of Wound Ostomy \& Continence Nursing. 2012;39(2):161-9.

[15] 15. Nazari B, Bakhshi S, Kaboudi M, Dehghan F, Ziapour A, Montazeri N. A Comparison of Quality of Life, Anxiety and Depression in Children with Cancer and Healthy Children, Kermanshah-Iran. International Journal of Pediatrics. 2017;5(7):5305-14.

[16] Montazeri N, Kianipour N, Nazari B, Ziapour A, Bakhshi S. Health Promoting Behaviors among University Students: A Case-Sectional Study of Kermanshah University of Medical Sciences. International Journal of Pediatrics. 2017;5(6):5091-9.

[17] O'shea ER, Wallace M, Griffin MQ, Fitzpatrick JJ. The effect of an educational session on pediatric nurses' perspectives toward providing spiritual care. Journal of pediatric nursing. 2011;26(1):34-43.

[18] Rigi Kootesh B, Raisi M, Ziapour A. Investigation of relationship between internet addict with mental health and quality sleep in students. Acta Medica Mediterranea. 2016;32(5):1921-5.

[19] Jalilian N, Ziapour A, Mokari Z, Kianipour N. A study of the relationship between the components of spiritual health and happiness of students at Kermanshah University of Medical Sciences in 2016 Annals of Tropical Medicine and Public Health. 2017;10(4):1010-4.

[20] Kaboudi M, Kianipour N, Ziapour A, Dehghan F. A Study of Health Literacy Components and their Relationships with Health-Promoting Behaviors in Students at Kermanshah University of Medical Sciences. International Journal of Pediatrics. 2017:5(12):6721-29.

[21] Gupta G. Spiritual intelligence and emotional intelligence in relation to self-efficacy and self-regulation among college students. International journal of social sciences \&interdisciplinary research. 2012;1(2):60-9.

[22] Mohammadi M, Esfandnia A, Rezaei S, Ziapour A. Performance evaluation of hospitals under supervision of kermanshah medical sciences using pabonlasoty diagram of a five-year period (2008-2012). Life Science Journal. 2014;11 (1):77-81.

[23] Mohammadi P, Kaboudi M, Ashtarian H, Matin BK, Rezaei M. The effects of educational intervention on the constructs of social cognitive theory and theory of planned behavior on cesarean intention among nulliparous pregnant women. Research Journal of Medical Sciences. 2016;10(2):43-8

[24] Golparvar M. Structural modeling of the relationship between spiritual connection with psychological capital and spiritual well-being of nurses. Quarterly Journal of Nursing Management. 2014;3(2):30-40.

[25] Culbertson SS, Fullagar CJ, Mills MJ. Feeling good and doing great: the relationship between psychological capital and well-being. Journal of occupational health psychology. 2010;15(4):421-23.
[26] Bayrami M, Movahedi Y. The Effectiveness of Social Skills Training on Psychological Capital Among University Students of Tabriz City. Quarterly Journal of Social Work. 2015;4(1):30-7.

[27] Taheri Kharameh Z, Sharififard F, Alizadeh M, Vahidabi V, Mirhoseini $\mathrm{H}$, Omidi R. An investigation of the relationship between spiritualreligious wellbeing and mental health in students. Qom University of Medical Sciences Journal. 2016;10(4):102-9.

[28] Brown J, Hanson JE, Schmotzer B, Webel AR. Spirituality and optimism: a holistic approach to component-based, self-management treatment for HIV. Journal of religion and health. 2014;53(5):1317-28.

[29] Khushde S, Farhangi M, Rigi kouteh B, Kahrazei F, Ziapour A. A comparative study of homesickness, depression, and internet addiction between native and nonnative students at University of Sistan and Baluchestan, Iran. Annals of Tropical Medicine and Public Health. 2017:10(6):1537-46

[30] Moradi M, Sadri Damirchi E, Khazan K, Dargahi S. The mediating role of psychological capital on the relationship between spiritual intelligence and job burnout. Journal of Occupational Health and Epidemiology. 2017;6(2):84-91.

[31] Mohammadi M, Raiegan AAV, Mirzaei M, Zahednezhad H, Jalali R, Abbasi P. Prevalence of underweight in iranian children: A systematic review and meta-analysis. Tehran University Medical Journal. 2018;76(4):241-9.

[32] Ghasemi-Jobaneh R, Zahrakar K, Hamdami M, Karimi K. Role of Spiritual Health and Mindfulness in Psychological Capital of Students of university of Guilan. Journal of Research in Medical Education. 2016;8(2):27-36.

[33] Jalali A, Bakhteh A, Esfandnia A, Kaboudi M. Internal evaluation of midwifery department of Kermanshah university medical sciences in 2015. Research Journal of Medical Sciences. 2016;10(3):164-8

[34] Paloutzian RF, Ellison CW. Loneliness, spiritual well-being and the quality of life. Loneliness: A sourcebook of current theory, research and therapy. 1982:224-37.

[35] O'Connor M, Guilfoyle A, Breen L, Mukhardt F, Fisher C. Relationships between quality of life, spiritual well-being, and psychological adjustment styles for people living with leukaemia: An exploratory study. Mental health, religion and culture. 2007;10(6):63147.

[36] Paloutzian RF, Park CL. Handbook of the psychology of religion and spirituality: Guilford Publications; 2014.

[37] Ziapour A, Pirsaheb M, Hemati L, Karimaei M, Asadi F, Azari A, et al. Epidemiological study of acute poisonings caused by consuming various contaminated food, chemical and pharmaceutical substances recorded by imam khomeini hospital of kermanshah during 4 years (2009-2012). Acta Medica Mediterranea. 2016;32(2):933-40.

[38] Ghasemi-Jobaneh R, Zahrakar K, Hamdami M, Karimi K. Role of Spiritual Health and Mindfulness in Psychological Capital of Students of university of Guilan. Research in Medical Education. 2016;8(2):2736.

[39] Womble MN, Labbé EE, Cochran CR. Spirituality and personality: understanding their relationship to health resilience. Psychological reports. 2013;112(3):706-15.

[40] Gnanaprakash C. Spirituality and resilience among post-graduate university students. Journal of Health Management. 2013;15(3):383-96.

[41] Fisher J. The four domains model: Connecting spirituality, health and well-being. Religions. 2011;2(1):17-28.

[42] Sessanna L, Finnell D, Jezewski MA. Spirituality in nursing and healthrelated literature: a concept analysis. Journal of Holistic Nursing. 2007;25(4):252-62.

[43] Charkhabi M, Abarghuei MA, Hayati D. The association of academic burnout with self-efficacy and quality of learning experience among Iranian students. Springerplus. 2013;2(1):677-85

[44] Lee SH, Jeon WT. The relationship between academic self-efficacy and academic burnout in medical students. Korean journal of medical education. 2015;27(1):27-35

[45] Sun T, Zhao XW, Yang LB, Fan LH. The impact of psychological capital on job embeddedness and job performance among nurses: a structural equation approach. Journal of advanced nursing. 2012;68(1):69-79.

[46] Indrianti R, Hadi C. Hubungan antara modal psikologis dengan keterikatan kerja pada perawat di instalasi rawat inap rumah sakit jiwa menur Surabaya. Jurnal psikologi industri dan organisasi. 2012:1(03):110-5.

[47] Malek-Khosravi S, Kaboudi M, Kaboudi B, Atefi G. Plasma homocysteine concentrations and insulin resistance in preeclampsia. Hypertension in Pregnancy. 2009;28(1):13-22. 